\title{
The Basis and Operation of Windcatcher in Architecture of Iran's Lut Desert Suburbs: Case Study of Shahdad, Iran
}

\author{
Mohammad Hojjat Changizi \\ Department of Architecture, Payam Noor University, Kerman Branch, Kerman, Iran
}

Email address:

mh.changizei@gmail.com

To cite this article:

Mohammad Hojjat Changizi. The Basis and Operation of Windcatcher in Architecture of Iran's Lut Desert Suburbs: Case Study of Shahdad, Iran. International Journal of Science, Technology and Society. Special Issue: Research and Practice in Architecture and Urban Studies in Developing Countries. Vol. 3, No. 2-1, 2015, pp. 27-30. doi: 10.11648/j.ijsts.s.2015030201.16

\begin{abstract}
Desert's winds in Iran often have high speed and undesirable quality. The architecture of these areas in suburbs of Lut desert has been contrasted to it as well, Iran has gained benefit from using windcatchers in natural ventilation and cooling the air for public and private spaces so much. This has provided hot rest by natural energy and in this direction, the building were breathing. so by advancing the technology and the materials and construction's methods it is gradually forgotten but obtained efficiency and basis of windcatcher during several century is a valuable gift for keeping the house from machine statue. In this regard, previous research studies and surveys with descriptive- analyzing method have been reviewed and applied for the quality of exploiting the basis and operation of windcatchers in today's architecture in Lut desert suburbs, especially the city of Shahdad.
\end{abstract}

Keywords: Windcatcher, Lute Edge Architecture, Natural Ventilation, Shahdad

\section{Introduction}

Since earlier years, Iranian architect has been able to find solutions for construction of the builds in each area of the country by considering the climate in accordance to the nature and increasing hot rest. Most of Iran's plateaus have been consisted of hot and dry districts, and therefore most traditional architecture have been arranged for hot and dry climate. The most important solution in traditional architecture in dry climate is applying the windcatcher. One of the most dried residential regions in Iran is suburbs of Lut desert because the intensity of the hot and dryness is very high. Cooling systems from both operational point and the costs and possibilities can not cause the rest of living in this region. On other hand, while the world moves toward exploiting the natural energy and decreasing pollution, Lut desert could be a potential advantage for energy source.

The windcatcher has caused desirable results from exploiting desert's wind and in this direction usage the basis and concepts which have been obtained in several thousound years and to seem that are able to cause concordant of architecture.

\section{Study Region: Shahdad and Lut Desert}

Shahdad is located in south rim of Lut desert in the province of Kerman which has special climate as like intensity of radiation, proportional low moisture, shortage of raining and high vapor which are characteristics of desert areas. Central pit of Lut desert have been mentioned as the hottest place of the world with the temperature above $70^{\circ} \mathrm{C}$. However, the temperature of the pits depends on the distance and closeness to the heights of adjacent regions and by going to inside of the desert, hot intensity and dryness will be increased. Low rain is one of the characteristic of desert and the main reason is high hot which prevent from saturation the humidity and another reason is Alborz and Zagross heights which prevent from penetration the humidity to desert. Proportional humidity is less than $30 \%$ yearly which sometimes reaches to zero.

\section{The Architecture of Lut Desert}

Lut desert's rim is accounted as a hot and dried region. Therefore, for certainty of hot and dried architecture principles some efforts have been made: 
a) to preserver the house from entry the sunshine b) the effective sun's hot on the wall of the building to be reached to minimum c) to prevent from coldness due to surface vapor (by using of air flow) d) hot exchange though wall of the building to be reached to the minimum e) to prevent from penetration of hot weather from weak connections and seams.

On the basis of above principles, the architecture on the rim of Lut desert has characteristics which are the same with the architecture in other hot and dried regions (figure 1). These specifications are as below:

using the material with high hot capacity- using of compressed plan designing- applying of dome roofindirectly connection the building onto ground. Using the door and windows in few number and small surface- usage ventilation equipment and lesser natural ventilationcompressed city texture and using light colors for external part of the building.

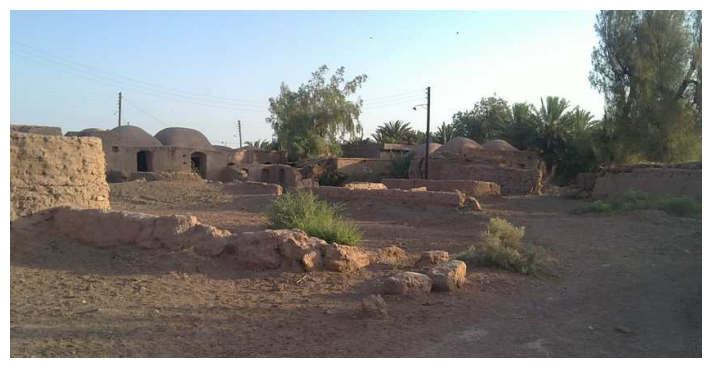

Figure 1. Architecture of southern Suburbs of the Lut desert.

A village in north of Shahdad

\section{Natural Ventilation}

Displacement of the inside air without using fossil energy is called natural ventilation. Ventilation in environmental control of the building to be done due to the following reasons:

1. Providing fresh air for the residents of the building 2 . Increasing the lost of the hot and vapor in the body (rest hot) 3 . Cooling inside of the building by changing the hot weather with outside cool weather (building's ventilation).

Two important methods in natural ventilation, transmissible ventilation and air cleaner ventilation, of course, the method of air cleaner has lesser speed and it needs possibilities and the space for ventilation. There is natural ventilation by exploring the pressure differences around the building and is based on 3 phenomenons: Wind speed, the direction of wind and temperature difference.

\subsection{Transmissible}

Transmissible ventilation occurs due to air pressure difference. The direction of coldness and ventilation are benefits of windcatcher, because of increasing the positive pressure toward the opening surface. The most efficient transmissible ventilation occurs when input opening is in the zone of full pressure and output opening is in low pressure zone. In transmissible ventilation, the arrangement and the quality of openings and their surfaces would be so important in designing.

\subsection{Air cleaner Ventilation}

Due to difference of air temperature, hot forces causes air cleaner ventilation, hot weather moves upside and cold air replace it. Air cleaner ventilation among the rooms will be increased by greater height between input and output openings. when the wind blows and outside temperature is lesser than the inside air, transmissible ventilation could be an effective coldness strategy but the wind is not available all the 24 hours of a day for example in the night, or in many climates, it's speed is slow or it might be site and local condition that causes unavailability of the wind for the building. In this situation air cleaner which is not required of replacing the air in the building, can create cold effect.

This method due to being independence from wind, has important advantage, in a room that becomes cold by air cleaner ventilation, the hot air goes up and exits from above opening of the room, the lack of the air trough the cold air which input from the down openings will be compensated. Such ventilation depends on the vertical height between input and output openings, their dimensions and the difference among outside temperature and medium temperature of above the room.

\section{Windcatcher}

Windcatcher as one special phenomenon in traditional architecture in Iran's dry region has an ancient history and ancient names such as Badgir, Badhanj,Vateghz, Batkhan, Khishon and Khishan show the remaining this phenomenon in the past and even today with modern equipments for desirable ventilation, windcatcher has importance in constructions of buildings in so many dry regions in Iran. In buildings which the wind is not available windcatcher can bring the wind inside the building from above the roof. Windcatchers have different shapes and are made on the basis of climate's situation of each region, especially the direction of the wind (desirable wind) in different regions.

Windcatchers on the basis of their pores are divided into different kinds such as square or four angle, eight angle or eight side, one angle and rectangular(certainly, the forms of khishan and Serchighi also to be manufactured).

In dry regions, air humidity is so low and during the day is far from rest scope so ventilation from the point of body's water balance and hot rest view, is not advisable. Clearing the sky causes that the air becomes cold at night time therefore buildings which have roof and thick walls due to keeping the inside air stable at all the day, are useful. The correct method in these regions, is keep opening the windows at night time and closing them on the days.

There are other traditional methods like using of windcatcher and cold rise of vapor by water pool and air tunnel.

The effect of windcatcher in cooling rooms have been greater because the body of the windcatcher channel was laid in underground and due to some humidity, vapor cold would 
affect the cooling. windcatcher causes air exchange and to exit the hot air when there is no wind they assist for exchanging the air in the space and they show the skill of Iranian architect for coordination with the environment, on the other hand windcatcher are phenomenon as symbolic aspect for hot and dry regions, it is not only a symbol but also shows an architecture concurred with the environment and in the direction of compatibility with it.

Windcatcher with the ground of right angle which have rod, to be produced somewhere that cold wind blows from north east to south west. These Windcatchers have two openings and have a wide surface toward cold wind and inside their rods, contrary with other Windcatchers, one opening is continuously open and is divided into two parts, the part facing to the wind that takes the air inside the building and another part which take out the air from inside the building. In four openings windcatchers the wind blows from every side, by one of the openings toward the inside and also exits by back opening. These windcatchers at inside of interior rod or body are divided into 4 parts in the shape of X (figure2) and this division will be continued to output of the windcatcher into a pool.

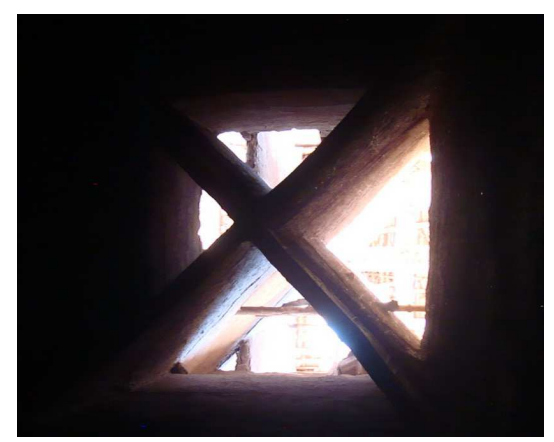

Figure 2. Inside the windcatcher, Sadeghi's house in shahdad

Availability of each building to the wind is difficult because the buildings toward the wind prevents the back buildings to touch the wind. In such cases the windcatcher on the roof could be exploited, there is both air cleaner and cool air which are useful for the building, of course in regions with suitable wind speed.

In making direction, the advantage of the windcatcher is that it could be used in any direction while the building direction might be affected by other factors as like sunshine.

In accordance to local wind direction, windcatcher to be designed, choosing windcatcher one, two or by multi direction should be on the basis of the amount and the wind direction for the months which the building needs cooling. In buildings with different usages like residential or reservoir, it could be seen that wind speed will be increased by becoming greater the height so this wind speed in the roof is greater than below stores and it could be possible for using of smaller openings toward the ground windows because on the roof, the wind has lesser obstacles, windcatcher can absorb the wind in every direction.

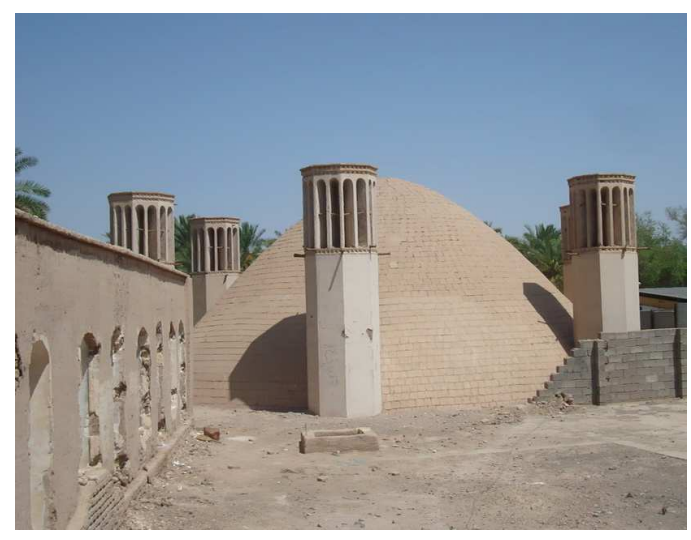

Figure 3. Windcatchers of cistern in Shahdad

\section{Discussion and Conclusion}

In windcatcher, Iranians applied several initiative in the basis which the most important of them is the body of windcatcher for making direction and the dimension and exploiting as absorber at the same time ( Bad khor) which draws the wind inside and exiting the wind(Bad Khan) and also are able to carry out transmissible and air cleaning ventilations. In continuation of passing through channels and some humid space, the dust will be decreased and the coldness will become greater. In this regard in Lut desert, in Shahdad the winds blow with high speed and have high pressure. Using the windcatcher with dimension and by it's form is difficult and expensive. Therefore, in these regions the winged walls (the walls next to opening for conducting air flow) to be used for direction and drawing the wind and also laying the openings in negative pressure zone that is back to wind and causes absorbing the air from the inside.

In most villages in the rim of Lut desert, there are subterranean channels which by fixing one Baad Khor(absorber the wind) and canalling toward buildings as getting closer to the spaces and channel surface to be decreased then the wind speed will be increased and in this case both ventilation and cooling the air will be provided. Laying fracture on the roof by two height levels as the lower level in the middle and the higher level to be located around it witch looks like a pit. By this solution the winds blow from each side through the walls with received filters, in the pit during ventilation the hot air because of negative pressure in that area to be exited back to the wind. Up to now, it has operated as windcatcher with this difference that the factor has been deleted and the wind could be reached to all areas by less difficulty.

\section{References}

[1] Reza Shatterin, climate and architecture, Simayea Danesh, 2009.

[2] Donald Watson, Kenneth Lab, Climatic Design: Energy-Efficient Building Principles and Practices, translation by vahid ghobadian and Mohammad Feiz Mahdavi, Tehran University, 2008. 
[3] Battle McCarthy Engineers, Wind Towers, translated by Mohammad Ahmadi Nejad, Khak, 2002.

[4] Mark DeKay, G.Z. Brown. Sun, Wind, and Light: Architectural Design Strategies, translated by Saeid Aghaeie, Ganj Honar, 2007.
[5] Cook, J. Cool houses for desert suburbs: optimizing heating and cooling for Arizona builders. Phoenix: Arizona Solar Energy Commission. 1979. 